\title{
Contributions of the EURO 2020 football championship events to a third wave of SARS-CoV-2 in Scotland, 11 June to 7 July 2021
}

Kimberly Marsh ${ }^{1}$, Emily Griffiths ${ }^{1}$, Johanna J. Young ${ }^{1}$, Carrie-Anne Gibb ${ }^{1}$, Jim McMenamin ${ }^{1}$

1. Public Health Scotland, Glasgow, Scotland

Correspondence: Kimberly Marsh (kimberly.marsh@phs.scot)

Citation style for this article:

Marsh Kimberly, Griffiths Emily, Young Johanna J., Gibb Carrie-Anne, McMenamin Jim. Contributions of the EURO 2020 football championship events to a third wave of SARS-CoV-2 in Scotland, 11 June to 7 July 2021. Euro Surveill. 2021;26(31):pii=2100707. https://doi.org/10.2807/1560-7917.ES.2021.26.31.2100707

Article submitted on 15 Jul 2021 / accepted on 03 Aug 2021 / published on 05 Aug 2021

Public Health Scotland used Scottish national contact tracing data to estimate the European football championship (EURO 2020) contributions to a third wave of SARS-CoV-2 infections. From 11 June to 7 July 2021, 2,632 (4\%) of 63,874 SARS-CoV-2 cases self-reported attending a EURO 2020 event; $90 \%$ were male, of whom $73 \%$ were 20-39-year-olds. Most cases attended unofficial gatherings and averaged more contacts than the general population. Targeted guidance on celebrating safely in closed spaces is key.

In early May 2021, Scotland entered a third wave of severe acute respiratory syndrome coronavirus 2 (SARS-CoV-2) infections. This wave was characterised by a 20-fold increase in diagnosed cases. The rapid rise, from a 7 -day cumulative incidence of 21 per 100,000 population to 427 cases per 100,000 population from 4 May to 3 July 2021, occurred alongside several notable events. These included the Delta variant (Phylogenetic Assignment of Named Global Outbreak (Pango) lineage designation B.1.617.2) overtaking Alpha (B.1.1.7) as the dominant strain circulating in Scotland [1], a gradual relaxation of lockdown restrictions [2] and the 2020 European football championship (EURO 2020). We used contact tracing data routinely collected through telephone interviews, undertaken as part of the 'Test and Protect' system implemented by the Scottish government [3], to describe the potential contributions of EURO 2020 to a third wave of SARSCoV-2 in Scotland.

\section{Scotland's participation in and recording of the EURO 2020 events in the contact tracing system}

From 11 June to 11 July 2021, Scotland and 10 other countries across Europe hosted 51 EURO 2020 matches. The Scottish football team participated in two matches at Hampden Park in Glasgow on 14 June and on 22 June. A third match took place at London's Wembley Stadium on 18 June 2021. Around 20,000 of the 5.5 million people resident in Scotland were reported to have travelled to London for the game, of whom 2,600 were allocated tickets into the Wembley Stadium [4].

Prior to the start of EURO 2020, we created 10 standard tags in the 'Test and Protect' contact tracing system to track attendance at EURO 2020 events among those testing positive for SARS-CoV-2. Interviewers were instructed to attach all relevant tags to a case's record whenever attendance was reported at a EURO 2020 event during the individual's infectious period. The infectious period in Scotland is defined as 2 days prior to and 9 days after symptom onset (or a positive test result if asymptomatic) for a total of 12 days. However, there is strong public messaging and an expectation that once diagnosed, cases will isolate and any nonhousehold contact exposure thereafter is minimal.

\section{Characteristics of Scottish SARS-CoV-2- positive cases during EURO 2020}

Using data abstracted from contact tracing interviews from 11 June to 7 July 2021, we identified 2,632 cases who self-reported attendance at EURO 2020-related events. The peak in cases occurred on 21 June 2021, 3 days after the England vs Scotland match at the Wembley Stadium (Figure 1) and declined gradually following Scotland's elimination from the championship on 22 June 2021. Approximately $4 \%$ of the 63,874 new SARS-CoV-2 cases reported in Scotland from 11 June to 7 July were related to EURO 2020. Travelling to London was reported by $61 \%$ of the 2,632 cases.

Public health messages about how to safely enjoy EURO 2020 games contrasted sharply with media coverage in Scotland showing large gatherings, especially of young men, attending EURO 2020-related events. Overall, $90 \%$ of the positive cases stemming from these events were male and $73 \%$ were aged $20-39$ years (Table 1 ). Similar age and sex patterns were observed in Scottish national data during and shortly after the EURO 2020 


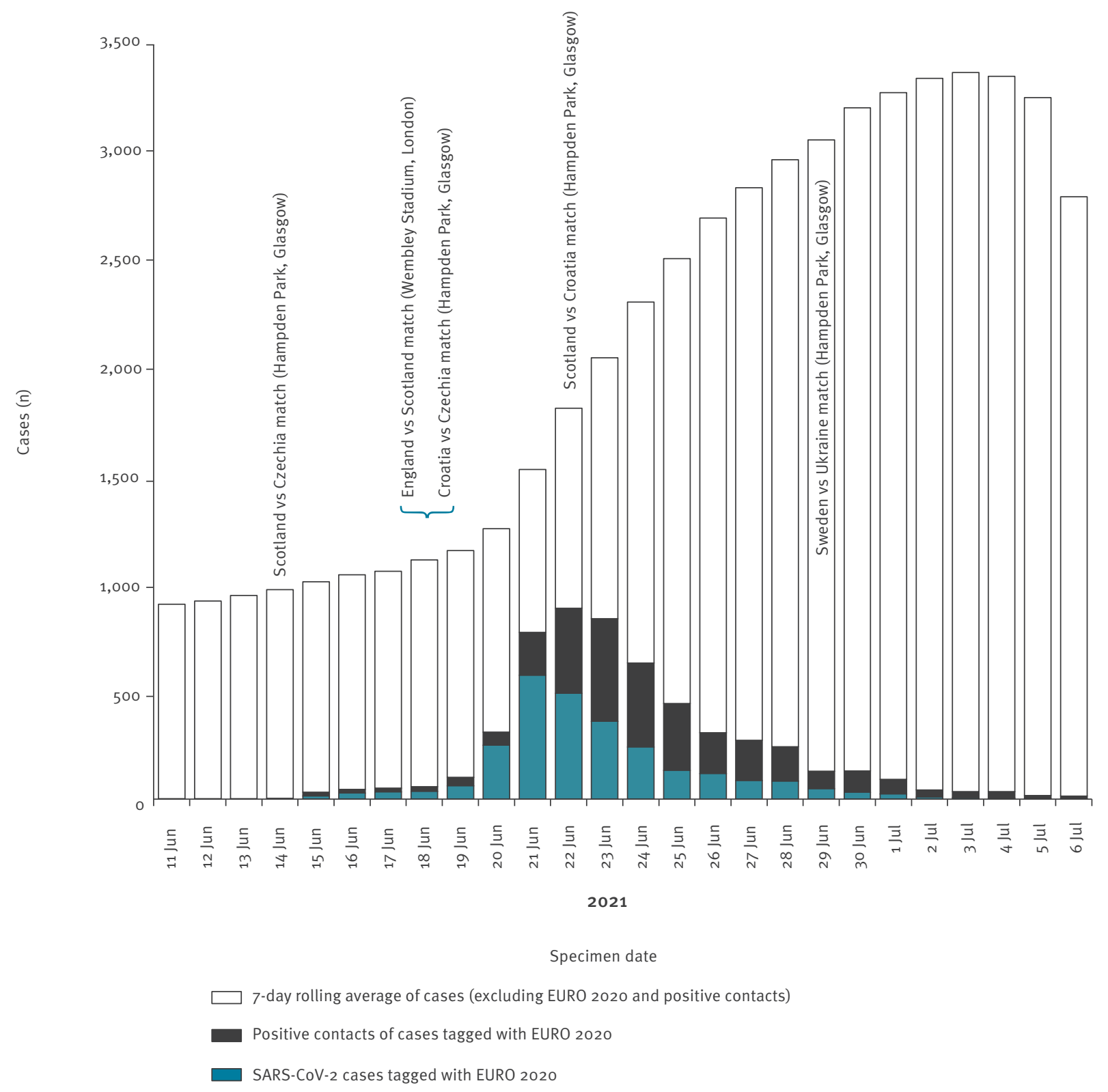

SARS-CoV-2: severe acute respiratory syndrome coronavirus 2.

matches; this is different from the previous two SARSCoV-2 waves where incidence rates among women typically exceeded those among men (Figure 2) [5].

We identified 2,970 separate events or tags related to the 2,632 SARS-CoV-2 infections from Scotland who attended EURO 2020 (Table 2). Attendance at a hospitality venue (e.g. a pub to watch a live match) was reported by 997 (34\%) cases. A review of free-text notes collected as part of the contact tracing process of 923 (31\%) cases that were tagged in the contact tracing system as 'EURO other settings' revealed different travel modes to attend EURO 2020 events in
London, most frequently by train, followed by private cars, flights and buses.

Attendance at the Scotland vs England match at the Wembley Stadium was the most commonly recorded official EURO 2020 event, with 452 (15\%) cases who reported attending. Two hundred and sixteen cases (7\%) reported attending four EURO 2020 matches held at Hampden Park in Glasgow, including the two in which the Scottish football team played. 


\section{TABLE 1}

SARS-CoV-2-positive cases stemming from EURO 2020 events $(\mathrm{n}=2,632)$ compared with all national infections $(n=63,874)$ by age and sex, Scotland, 11 June-7 July 2021

\begin{tabular}{|c|c|c|c|c|c|c|c|c|c|c|c|c|c|c|c|c|}
\hline \multirow[b]{3}{*}{$\begin{array}{l}\text { Age group } \\
\text { (years) }\end{array}$} & \multicolumn{8}{|c|}{ SARS-CoV-2-positive cases related to EURO 2020} & \multicolumn{8}{|c|}{ All infections from national contact tracing data } \\
\hline & \multicolumn{2}{|c|}{ Male } & \multicolumn{2}{|c|}{ Female } & \multicolumn{2}{|c|}{ Unknown } & \multicolumn{2}{|c|}{ Total } & \multicolumn{2}{|c|}{ Male } & \multicolumn{2}{|c|}{ Female } & \multicolumn{2}{|c|}{ Unknown } & \multicolumn{2}{|c|}{ Total } \\
\hline & $\mathrm{n}$ & $\%$ & $\mathrm{n}$ & $\%$ & $\mathrm{n}$ & $\%$ & $\mathrm{n}$ & $\%$ & $\mathrm{n}$ & $\%$ & $\mathrm{n}$ & $\%$ & $\mathrm{n}$ & $\%$ & $\mathrm{n}$ & $\%$ \\
\hline $0-5$ & 0 & 0 & 2 & 1 & 0 & 0 & 2 & 0 & 974 & 3 & 988 & 3 & 2 & 0 & 1,964 & 3 \\
\hline $6-19$ & 351 & 15 & 43 & 17 & 0 & 0 & 394 & 15 & 8,007 & 24 & 7,676 & 26 & 31 & 7 & 15,714 & 25 \\
\hline $20-39$ & 1,738 & 73 & 148 & 58 & 1 & 100 & 1,887 & 72 & 16,811 & 50 & 12,918 & 44 & 246 & 54 & 29,975 & 47 \\
\hline $40-59$ & 235 & 10 & 54 & 21 & 0 & 0 & 289 & 11 & 6,308 & 19 & 6,354 & 22 & 128 & 28 & 12,790 & 20 \\
\hline $60-79$ & 50 & 2 & 10 & 4 & 0 & 0 & 60 & 2 & 1,565 & 5 & 1,346 & 5 & 9 & 2 & 2,920 & 5 \\
\hline$\geq 80$ & 0 & 0 & 0 & 0 & 0 & 0 & NA & 0 & 212 & 1 & 228 & 1 & 1 & 0 & 441 & 1 \\
\hline Unknown & 0 & 0 & 0 & 0 & 0 & 0 & NA & 0 & 17 & 0 & 17 & 0 & 36 & 8 & 70 & 0 \\
\hline Total & 2,374 & 100 & 257 & 100 & 1 & 100 & 2,632 & 100 & 33,894 & 100 & 29,527 & 100 & 453 & 100 & 63,874 & 100 \\
\hline
\end{tabular}

NA: not available; SARS-CoV-2: severe acute respiratory syndrome coronavirus 2.

\section{FIGURE 2}

Wave dynamics of SARS-CoV-2-positive cases, 7-day rolling average incidence rate per 100,000 for all ages and ages 20-39 years, by sex, Scotland, 12 February 2020-14 July 2021( $\mathrm{n}=323,933$ cumulative SARS-CoV-2-positive cases)

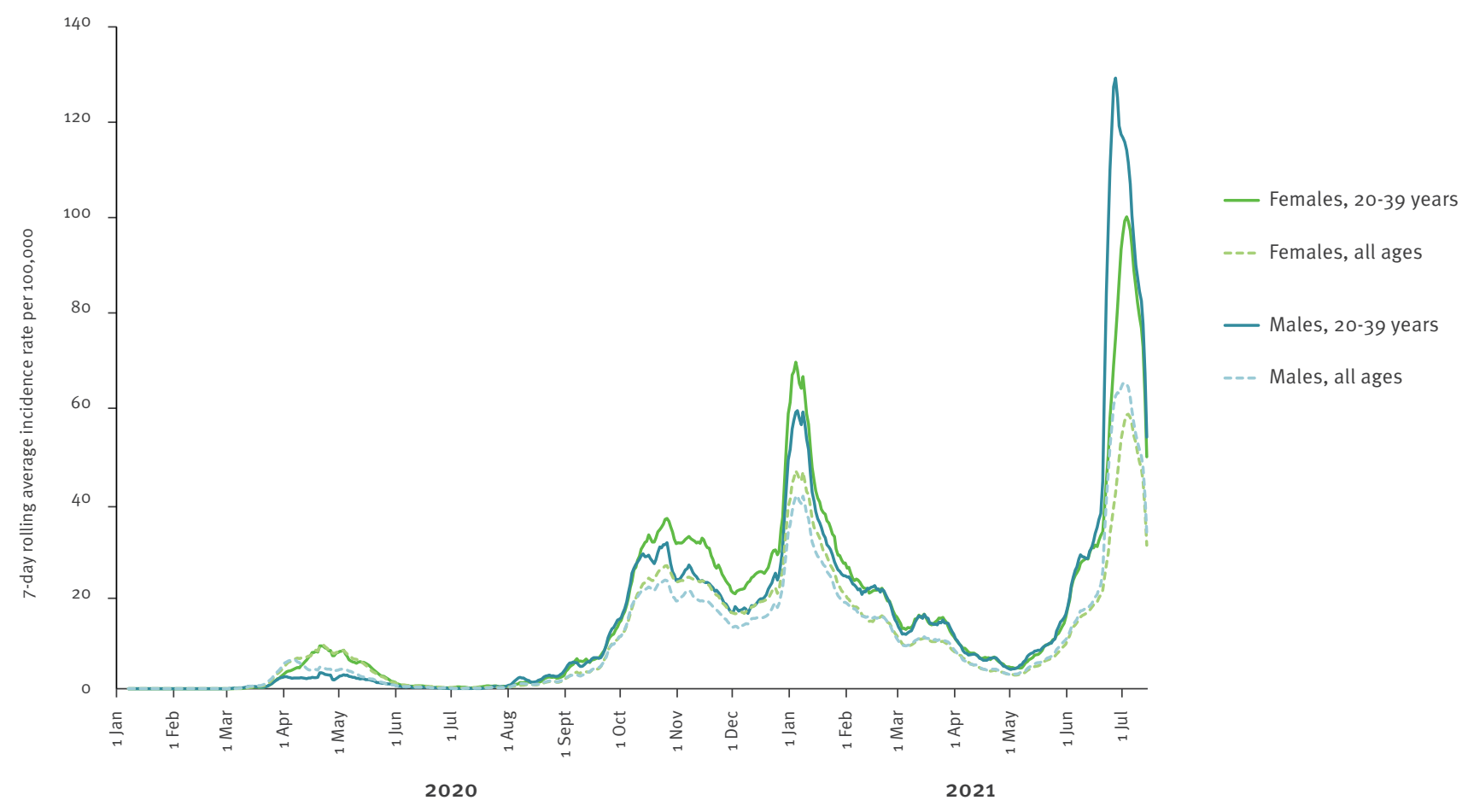

SARS-CoV-2: severe acute respiratory syndrome coronavirus 2. 
Case definitions and numbers of SARS-CoV-2-positive cases related to EURO 2020 tags coded by Scotland's contact tracing teams, Scotland, 11 June-7 July $2021(\mathrm{n}=2,970)$

\begin{tabular}{|c|c|c|c|}
\hline \multirow{2}{*}{$\begin{array}{l}\text { Tag in the contact tracing system for SARS-CoV-2- } \\
\text { positive cases related to EURO } 2020\end{array}$} & \multirow{2}{*}{ Case definition } & \multicolumn{2}{|c|}{ Frequency } \\
\hline & & $\mathrm{n}$ & $\%$ \\
\hline EURO hospitality & $\begin{array}{l}\text { Attended hospitality setting associated with EURO } 2020 \text { (e.g. pub } \\
\text { showing a live match) }\end{array}$ & 997 & 33.6 \\
\hline EURO other settings & $\begin{array}{l}\text { Attended a gathering from } 11 \text { June to } 11 \text { July. This tag was used when } \\
\text { the case/contact attended a gathering associated with EURO } 2020 \text { that } \\
\text { did not take place in a football stadium, hospitality setting, fan zone, } \\
\text { or house party (indoors/outdoors). }\end{array}$ & 923 & 31.1 \\
\hline $\begin{array}{l}\text { EURO attended England vs Scotland match Wembley } \\
\text { Stadium, London, } 18 \text { June } 2020\end{array}$ & $\begin{array}{l}\text { Attended England vs Scotland match at Wembley Stadium, London, } 18 \\
\text { June } 2021\end{array}$ & 452 & 15.2 \\
\hline EURO attended house party & $\begin{array}{l}\text { Attended a private residence for an event associated with EURO } 2020 \\
\text { (e.g. a house party to watch a match) }\end{array}$ & 239 & 8.0 \\
\hline $\begin{array}{l}\text { EURO attended Scotland vs Croatia match, Hampden } \\
\text { Park, Glasgow, } 22 \text { June } 2021\end{array}$ & $\begin{array}{l}\text { Attended Scotland vs Croatia match at Hampden Park, Glasgow, } 22 \\
\text { June } 2021\end{array}$ & 131 & 4.4 \\
\hline EURO fan zone Glasgow Green & Attended fan zone in Glasgow Green from 11 June to 11 July 2021 & 84 & 2.8 \\
\hline EURO attended match, Wembley Stadium, London & $\begin{array}{l}\text { Attended any match other than the England vs Scotland match on } 18 \\
\text { June } 2021\end{array}$ & 59 & 2.0 \\
\hline $\begin{array}{l}\text { EURO attended Scotland vs Czechia match, Hampden } \\
\text { Park, } 14 \text { June } 2021\end{array}$ & $\begin{array}{l}\text { Attended Scotland vs Czechia match at Hampden Park, Glasgow, } 14 \\
\text { June } 2021\end{array}$ & 48 & 1.6 \\
\hline $\begin{array}{l}\text { EURO attended Croatia vs Czechia match, Hampden } \\
\text { Park, } 18 \text { June } 2021\end{array}$ & $\begin{array}{l}\text { Attended Croatia vs Czechia match at Hampden Park, Glasgow, } 18 \text { June } \\
\qquad 2021\end{array}$ & 26 & 0.9 \\
\hline $\begin{array}{l}\text { EURO attended Sweden vs Ukraine match, Hampden } \\
\text { Park, } 29 \text { June } 2021\end{array}$ & $\begin{array}{l}\text { Attended Sweden vs Ukraine match at Hampden Park, Glasgow, } 29 \\
\text { June } 2021\end{array}$ & 11 & 0.4 \\
\hline
\end{tabular}

SARS-CoV-2: severe acute respiratory syndrome coronavirus 2.

\section{Numbers of close contacts and secondary attack rates}

Using contact tracing data, it was possible to estimate average number of contacts and secondary attack rates. The EURO 2020 index cases reported on average 5.6 close contacts vs 3.2 in the general population between 11 June and 7 July 2021. Secondary attack rates were significantly higher for EURO 2020 index cases $(27.2 \%)$ than non-EURO 2020 cases $(24.1 \%)$ (Z-score 6.99; $\mathrm{p}<0.00001)$. On 22 June, an estimated $51 \%$ of all Scottish SARS-CoV-2-positive cases reported attendance at a EURO 2020 event or were close contacts of someone who had attended (Figure 1).

Six days later, Scotland reported its highest number of daily cases ever of 3,930 [5]. Since 3 July 2021, the 7-day rolling average case numbers suggest that Scotland's third wave is receding.

\section{Discussion}

This analysis of the still-evolving third wave of SARSCoV-2 in Scotland that coincided with the EURO 2020 games illustrates the potential impact of large sporting events on the trajectory of a country's epidemic. At its peak, more than half of the cases reported in Scotland either attended a EURO 2020 event or were close contacts of someone who had attended. This is not surprising, given that the country's return to the Union of European Football Associations EURO competition after 23 years offers an opportunity for celebration.
Our results suggest that the steep increase in cases among men aged 20-39 years probably occurred as a result of more frequent social gatherings surrounding the EURO 2020 matches, rather than from official EURO 2020 events. At official EURO matches and fan zones, efforts were made to ensure proper ventilation and encourage social distancing [6]. In the case of the Wembley Stadium, attendees were required to show a negative lateral flow device test result within $48 \mathrm{~h}$ of the time the stadium gates were opened or proof of full vaccination (received at least 14 days before the match) before being allowed entry into the stadium. These measures probably decreased the risk of transmission of SARS-CoV-2 during official events. Data confirming this hypothesis are not yet available.

Higher case rates among the younger male population also likely occurred as a result of low vaccination coverage in this age group. At the time of the EURO 2020 games, around $19 \%$ of men aged $18-29$ years and 30\% of men aged 30-39 years were fully vaccinated [7]. Vaccination coverage was also lower among men compared with women in both age groups. Compared with previous SARS-CoV-2 waves, case rates among men exceeded those among women during the third wave, especially among younger men aged 20-39 years.

Critically, our study showed that EURO 2020 cases had a higher average number of contacts and a higher secondary attack rate than the general population. The majority of the cases reported attending unofficial 
EURO 2020 events linked to smaller gatherings such as house parties, visits to pubs and restaurants, as well as extended travel highlighting a need for targeted guidance on how to safely celebrate in small informal gatherings with appropriate social distancing, proper ventilation and mask wearing in closed spaces. Evidence of the potential risks in transmitting SARSCoV-2 in vehicles is especially well documented [8], yet travel to London by private cars and public buses were common.

While this analysis suggests that the behaviour and events surrounding EURO 2020 games (as opposed to match attendance itself) uniquely contributed to Scotland's third COVID-19 wave, causality cannot be proven. To do so, similar information about behaviours of the uninfected population related to participation at EURO 2020 events is needed. A similar picture of rising cases has emerged elsewhere in Europe where games have been held, with a $10 \%$ increase in cases in the week leading up to 27 June 2021 [9]. The EURO 2020-related transmissions have also been documented in Finland, where 947 new SARS-CoV-2-positive cases were linked to travel to the host city Moscow, Russia [10].

It is not possible to say whether EURO 2020 cases acquired or transmitted infection while attending a specific event, especially in light of rising background prevalence. The EURO 2020 games occurred alongside other events in Scotland that could have contributed to a rise in cases, including the introduction of the potentially more transmissible SARS-CoV-2 Delta variant and an easing of lockdown measures just before the matches.

Because this analysis uses self-reported data and some people may be reluctant to admit risky behaviours, the number of EURO 2020 cases reported is likely to be an underrepresentation of the actual number. At the same time, PCR testing uptake in Scotland increased by more than 50\% from May to July 2021 [11], thus increasing case detection rates during this third wave. Further work to establish linkages between EURO 2020 and non-EURO 2020 cases using genetic sequencing are underway.

\section{Conclusion}

Our results suggest a clear link between the increase in SARS-CoV-2-positive cases among men aged 20-39 years and the EURO 2020. The behaviour surrounding attendance at EURO 2020-related events rather than match attendance itself may have uniquely contributed to Scotland's third wave. Increased social mixing and travel to London surrounding the games is likely to have increased cases among young men, who currently have lower vaccination coverage than the older population. Public health messaging that acknowledges the unique types of risks surrounding these events and educates people about how to best manage them is critical when planning for future large sporting events.
Early exit of the Scottish football team from the EURO 2020 may have contributed to the subsequent reduction in cases that are now being observed.

\section{Acknowledgements}

The authors would like to thank Allan McLeod, Alice Whettlock, April Went, Beth Findlay, Ciaran Harvey, David Henderson, Isobel Mclachlan, Edward McArdle, Eisin McDonald, Genna Drennan, Leonardo I Green, Louise Nicol, Sema Nickbakhsh, Melissa Llano, Paul Bett, Ross Cameron, Nicolaos Christofidis, Theresa Ryan, Amanda Weir, and Victoria Ponce Hardy of the Public Health Scotland Real Time Epidemiology team and Maureen Duff in the Clinical and Protecting Health Directorate for their contribution to the data collection and reporting. Special thanks are also extended to the Test and Protect Contact Tracing practitioners and Nick Phin and David Goldberg who reviewed the manuscript as part of Public Health Scotland's scientific clearance process. We appreciate the contributions of the Eurosurveillance team for their editorial review.

\section{Conflict of interest}

None declared.

\section{Authors' contributions}

$\mathrm{KM}$ drafted and coordinated the preparation of the manuscript. KM, EG, JJY, CAG and JM contributed to the analysis of the data. All authors reviewed the manuscript and JM provided expert advice on finalising the manuscript. All authors approved the final version.

\section{References}

1. Sheikh A, McMenamin J, Taylor B, Robertson C, Public Health Scotland and the EAVE II Collaborators. SARS-CoV-2 Delta VOC in Scotland: demographics, risk of hospital admission, and vaccine effectiveness. Lancet. 2021;397(10293):24612. https://doi.org/10.1016/S0140-6736(21)01358-1 PMID: 34139198

2. The Scottish Parliament. Timeline of Coronavirus (COVID-19) in Scotland. Edinburgh: The Scottish Parliament; 2021. Available from: https://spice-spotlight.scot/2021/07/09/ timeline-of-coronavirus-covid-19-in-scotland

3. National Health Service Scotland (NHS inform). Test and Protect. Help stop the spread of coronavirus (COVID-19). Edinburgh: NHS inform; 2021. Available from: https://www. nhsinform.scot/campaigns/test-and-protect

4. BBC News. Euro 2020: Thousands of Scotland fans gather in central London. London: BBC; 18 June 2021. Available from: https://www.bbc.co.uk/news/uk-scotland-57516928

5. Public Health Scotland. COVID-19 daily dashboard. Edinburgh: Public Health Scotland; 2021. Available from: https:// public.tableau.com/app/profile/phs.covid.19/viz/COVID19DailyDashboard_15960160643010/Overview\#!/vizhome/ COVID-19DailyDashboard_15960160643010/Overview

6. Union of European Football Associations (UEFA). COVID-19 guidance for your EURO 2020 match. [Accessed: 13 Jun 2021]. Available from: https://www.uefa.com/uefaeuro-2020/ event-guide/london/stadium/

7. Public Health Scotland. Daily trend of vaccinations by age group and sex. Edinburgh: Public Health Scotland; 2021. Available from: https://www.opendata. nhs.scot/dataset/covid-19-vaccination-in-scotland/ resource/9b99e278-b8d8-47df-8d7a-a8cf98519ac1

8. Jayaweera M, Perera H, Gunawardana B, Manatunge J. Transmission of COVID-19 virus by droplets and aerosols: A critical review on the unresolved dichotomy. Environ Res. 2020;188:109819. https://doi.org/10.1016/j. envres.2020.109819 PMID: 32569870

9. World Health Organization (WHO). Weekly epidemiological update on COVID-19-29 June 2021. Emergency Situational 
Updates. Edition 46. Geneva: WHO; 29 June 2021.

Available from: https://www.who.int/publications/m/item/

weekly-epidemiological-update-on-covid-19---29-june-2021

10. Finnish institute for health and welfare. COVID-19 cases on

the rise again in Finland - infections reported particularly

among Euro 2020 football fans returning from Russia. Helsinki:

THL; 2021. Available from: https://thl.fi/en/web/thlfi-en/-/

covid-19-cases-on-the-rise-again-in-finland-infections-

reported-particularly-among-euro-2020-football-fans-

returning-from-russia

11. Scottish Government. Coronavirus (COVID-19): trends

in daily data. Edinburgh: Scottish Government; 2021.

Available from: https://www.gov.scot/publications/

coronavirus-covid-19-trends-in-daily-data

\section{License, supplementary material and copyright}

This is an open-access article distributed under the terms of the Creative Commons Attribution (CC BY 4.0) Licence. You may share and adapt the material, but must give appropriate credit to the source, provide a link to the licence and indicate if changes were made.

Any supplementary material referenced in the article can be found in the online version.

This article is copyright of the authors or their affiliated institutions, 2021. 